\title{
Urine cyclic nucleotide concentrations in cancer and other conditions; cyclic GMP: a potential marker for cancer treatment
}

\author{
GA TURNER, RD ELLIS, D GUTHRIE, ${ }^{*}$ AL LATNER, $\dagger$ JM MONAGHAN, \\ AW SKILLEN, RG WILSON*
}

From the University Departments of Clinical Biochemistry and Metabolic Medicine and $†$ Microbiological Chemistry, Newcastle upon Tyne, *Newcastle General Hospital, Newcastle upon Tyne, and $\ddagger$ Queen Elizabeth Hospital, Gateshead

SUMMARY Cyclic guanosine $3^{\prime}, 5^{\prime}$ monophosphate (cyclic GMP) and cyclic adenosine $3^{\prime}, 5^{\prime}$ monophosphate (cyclic AMP) have been determined in random urine specimens from 95 healthy individuals, 60 patients with non-cancerous conditions, 52 patients with benign tumours, and 74 patients with malignant tumours. Concentrations of cyclic GMP have also been determined in a number of other groups, including some undergoing cancer treatment. Ninety-three per cent of cancer patients had raised urinary cyclic GMP concentrations compared to the reference range for healthy subjects. For the non-cancerous and benign groups, $33 \%$ and $42 \%$ respectively had raised concentrations. The urine cyclic AMP concentrations were similar in all groups.

Urine cyclic GMP appeared to rise early in the onset of malignant growth. Successful cancer treatment was accompanied by a dramatic fall in the urine cyclic GMP concentrations, whereas if the treatment was unsuccessful the level did not change. It is concluded that urine cyclic GMP may have important applications in the monitoring of cancer treatment.

A number of studies have suggested that cyclic guanosine $3^{\prime}, 5^{\prime}$ monophosphate is raised in cancer tissue. $^{1-4}$ Furthermore, increased cyclic GMP concentrations have been detected in the urine of cancer-bearing animals ${ }^{56}$ and cancer patients. ${ }^{7-11}$ For a number of reasons, this substance appeared to be particularly attractive for use as an indicator of tumour status. Firstly, its excretion is apparently not modified by the kidney ${ }^{12}$ and once excreted its activity in the urine is very stable. ${ }^{13}$ Secondly, it is excreted in the urine in quantities that far exceed the detection limits for the chosen method of assay (radioimmunoassay). Finally, as in vitro studies indicate, this substance is directly involved with growth regulation; ${ }^{14}$ this makes it a suitable biochemical parameter to measure in relation to cancer.

In the present study, cyclic GMP was assayed in single urine specimens taken from groups of healthy individuals, and patients with cancerous and noncancerous disorders. The level of cyclic AMP was also determined on the same specimens. Although

Accepted for publication 23 December 1981 no convincing evidence exists to suggest that cyclic AMP alone might be useful as a general tumour marker, it was felt that, in view of the intimate association previously shown between cyclic GMP and cyclic AMP from cellular in vitro studies, ${ }^{14}$ a similar association might exist in urine and extend the usefulness of cyclic GMP as a tumour marker.

\section{Material and methods}

Single urine specimens were collected from patients and healthy individuals at random times between $09.00 \mathrm{~h}$ and $17.00 \mathrm{~h}$. These groups were designated "healthy", "non-cancerous", "benign" and "malignant". The healthy group consisted of healthy volunteers ( 73 women and 22 men) and had a mean age of $36.8 \mathrm{yr}$ (range 20-69 yr). The non-cancerous group consisted of individuals (45 women and 15 men) suffering from a variety of non-cancerous disorders; their mean age was $39.3 \mathrm{yr}$ (range 18-75 yr). Further details of the composition of this latter group are given in Table 1. The benign group consisted of 52 women with benign tumours ( 30 benign breast lesions, 17 benign gynaecological lesions and 800 
Table 1 Urine cyclic GMP concentrations in patients with non-cancerous disorders

\begin{tabular}{|c|c|c|c|}
\hline \multirow[t]{2}{*}{ Group } & \multicolumn{2}{|c|}{$\begin{array}{l}\text { Urine cyclic GMP* } \\
\text { ( } \mu \text { mol/g creatinine) }\end{array}$} & \multirow[t]{2}{*}{$\begin{array}{l}\text { Percentage increase compared with } \\
\text { healthy group }\end{array}$} \\
\hline & Median & Range & \\
\hline Healthy (95) & $0 \cdot 31$ & $0.09-0.66$ & - \\
\hline Psoriasis (6) & $0 \cdot 36$ & $0 \cdot 28-0 \cdot 64$ & 0 \\
\hline \multirow{7}{*}{$\begin{array}{l}\text { Mild upper respiratory tract } \\
\text { infection (10) } \\
\text { Allergic disorders (6) } \\
\text { Miscellaneous infections (7) } \\
\text { Gastrointestinal disorders (7) } \\
\text { Bronchitis (5) } \\
\text { Severe upper respiratory tract } \\
\text { infections (9) }\end{array}$} & & & \\
\hline & 0.49 & $0 \cdot 31-1 \cdot 00$ & 10 \\
\hline & 0.54 & $0.27-0.99$ & 33 \\
\hline & $0 \cdot 64$ & $0.24-0.96$ & 43 \\
\hline & 0.69 & $0.21-1.07$ & 57 \\
\hline & $0 \cdot 67$ & $0.42-1 \cdot 04$ & 60 \\
\hline & 0.88 & $0.53-1.47$ & 78 \\
\hline
\end{tabular}

${ }^{*}$ All disease groups were significantly different from healthy group $(\mathrm{p}<0.001)$ except for group of patients with psoriasis $(\mathrm{p}>0.05)$.

In Tables $1-5,1 \mu \mathrm{mol} / \mathrm{g}$ creatinine $\equiv 113 \mu \mathrm{mol} / \mathrm{mol}$ creatinine.

5 benign lesions which had arisen in other sites). The benign nature of their lesions was confirmed by histological examination of biopsy specimens. The mean age of this latter group was 39.1 yr (range 32-69 yr). The malignant group consisted of individuals (68 women and 6 men) with a clinically diagnosed and histologically proven cancer. The mean age of this group was $56 \cdot 5 \mathrm{yr}$ (range $32-82 \mathrm{yr}$ ). Although the mean age of the malignant group was higher than that of the healthy group, two recent studies $^{13}{ }^{15}$ have shown that urine cyclic nucleotide excretion is unaffected by age.

The composition of the malignant group was as follows: 13 were women with an adenocarcinoma of the ovary (stage I to IV FIGO classification); 13 were women with an adenocarcinoma of the ovary (stages III/IV) who had undergone a laparotomy one week before in which different amounts of tumour had been removed, and in all these cases tumour tissue still remained in the abdomen; 21 were women with localised or disseminated carcinoma of the breast; 15 were women with squamous carcinoma of the cervix (stages II to IV, FIGO classification); 12 were men and women with advanced cancers arising in various other sites (mainly adenocarcinomas of the stomach and large bowel).

Apart from the 13 ovarian cancer patients who had had a laparotomy, none of the other individuals in the three major disease groups had received treatment for their condition before collecting the urine. Furthermore, none of the healthy group was taking drugs other than oral contraceptives. For all individuals, details of age and sex were noted, and for the healthy group details of stage of menstrual cycle and use of oral contraceptives were noted where relevant.

In addition to these four major groups, urine specimens were collected from a number of other smaller groups of patients. One group consisted of women who attended hospital as a consequence of a positive (grade IV) cervical-smear test, subsequent histological examination confirming the presence of cervical intraepithelial neoplasia. A second group consisted of women who had had an operation to correct a prolapse. Urine specimens were collected one day before and seven days after this operation. The data from the preoperative specimens were included also in the non-cancerous group. A third sub-group consisted of 10 individuals from the malignant group who had had all their tumour removed surgically. These patients subsequently provided another specimen of urine one to two weeks after the operation. This group comprised five patients with carcinoma of the cervix, three patients with carcinoma of the breast and two patients with carcinoma of the rectum. One other group consisted of women with stage III or IV ovarian carcinoma who had undergone cytotoxic therapy. Treatment of this group of patients consisted of chemotherapy with a combination of cyclophosphamide and gestronol (Depostat) after incomplete surgical removal of their tumours. These patients also received Levamisole or a placebo as part of a double-blind trial. The cytotoxic therapy was started one week after the diagnostic laparotomy, and urine specimens were collected one to seven months later whilst the patients were still on cytotoxic therapy, at which time the patients were classified as either having complete clinical remission or no remission.

After collection, all specimens were stored at $-20^{\circ} \mathrm{C}$. Cyclic AMP was assayed by a proteinbinding method as previously described. ${ }^{16}$ Cyclic GMP was assayed using a radioimmunoassay kit supplied by the Radiochemical Centre, Amersham. Creatinine was determined by the Jaffé reaction using a method based on that described by Popper et al. ${ }^{17}$ All specimens were assayed for cyclic nucleotides and creatinine in a blind fashion. Results were expressed as micromoles of cyclic nucleotide 
excreted per gram of creatinine. All differences between groups were analysed statistically using the Mann-Whitney $U$ test, except for the data given in Table 4, which was analysed by the Wilcoxon paired analysis.

\section{Results}

Preliminary inspection of the data from the healthy group indicated that neither sex nor age nor the use of oral contraceptives affected the range of urine cyclic GMP or cyclic AMP concentrations. It was found, however, that concentrations were affected by the stage of the menstrual cycle. For weeks 1 and 2 , the ranges for cyclic GMP and cyclic AMP were $0 \cdot 11-0.36 \mu \mathrm{mol} / \mathrm{g}$ creatinine (median $0.20 \mu \mathrm{mol} / \mathrm{g}$ creatinine; 9 observations) and 1.0-2.7 $\mu \mathrm{mol} / \mathrm{g}$ creatinine (median $1.3 \mu \mathrm{mol} / \mathrm{g}$ creatinine; 9 observations) respectively. For weeks 3 and 4 , the ranges for cyclic GMP and cyclic AMP were 0.11-0.66 $\mu \mathrm{mol} / \mathrm{g}$ creatinine (median $0.39 \mu \mathrm{mol} / \mathrm{g}$ creatinine; 21 observations) and $1.3-4.7 \mu \mathrm{mol} / \mathrm{g}$ creatinine $(2 \cdot 8$ $\mu \mathrm{mol} / \mathrm{g}$ creatinine; 21 observations) respectively. Although the values for weeks ( 1 and 2$)$ and ( 3 and 4) are significantly different (cyclic GMP $p<0.02$; cyclic AMP $p<0.05$ ), when the ranges for the two groups are taken together they are very similar to those ranges obtained for urine cyclic GMP and cyclic AMP in post-menopausal women (cyclic GMP 0.13-0.57 $\mu \mathrm{mol} / \mathrm{g}$ creatinine, cyclic AMP $0.85-4.7 \mu \mathrm{mol} / \mathrm{g}$ creatinine; 13 observations). It was considered, therefore, that the contribution by this factor to the overall cyclic nucleotide excretion was not of sufficient importance and magnitude to necessitate it being taken into account in the analysis of the data from the other groups of patients.

Figure 1 compares urine cyclic GMP concentrations in the different groups; $93 \%, 42 \%$, and $33 \%$ of the urines in the malignant, benign, and noncancerous groups respectively håve cyclic GMP concentrations which are higher than those in the healthy group; all disease groups are significantly different from the healthy group ( $p<0.001)$. Also, the malignant group is significantly different from all the other groups $(p<0.001)$. The median urine cyclic GMP concentration for the malignant group is nearly four times higher than the median value for the healthy group and twice as high as the median values for the non-cancerous and benign groups.

Figure 2 compares urine cyclic AMP concentrations in the healthy group with those in the other three groups. There are no significant differences $(p$ $>0.05$ ) between groups. The ratio of cyclic AMP to cyclic GMP was also calculated for all the urines and the results are given in Fig. 3. As might be expected, the picture is the converse to that described for

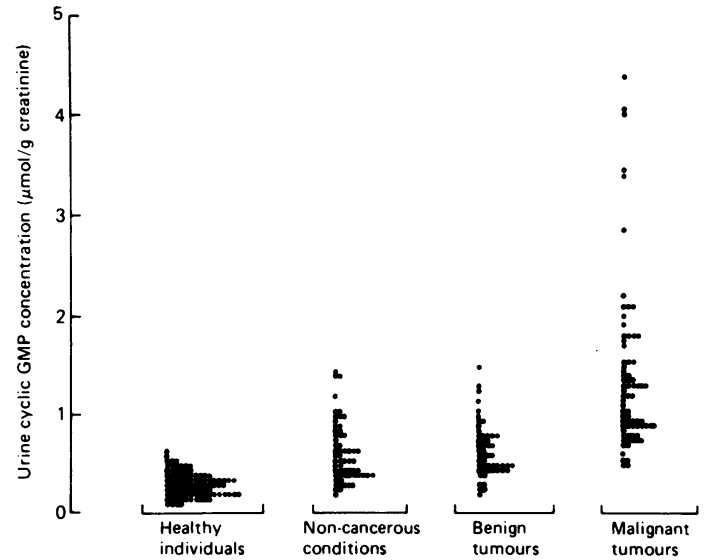

Fig. 1 Urine cyclic GMP concentrations in healthy individuals and in patients with non-cancerous conditions, benign tumours, or malignant tumours.

In Figs. $1-3,1 \mu \mathrm{mol} / \mathrm{g}$ creatinine $\equiv 113 \mu \mathrm{mol} / \mathrm{mol}$ creatinine.

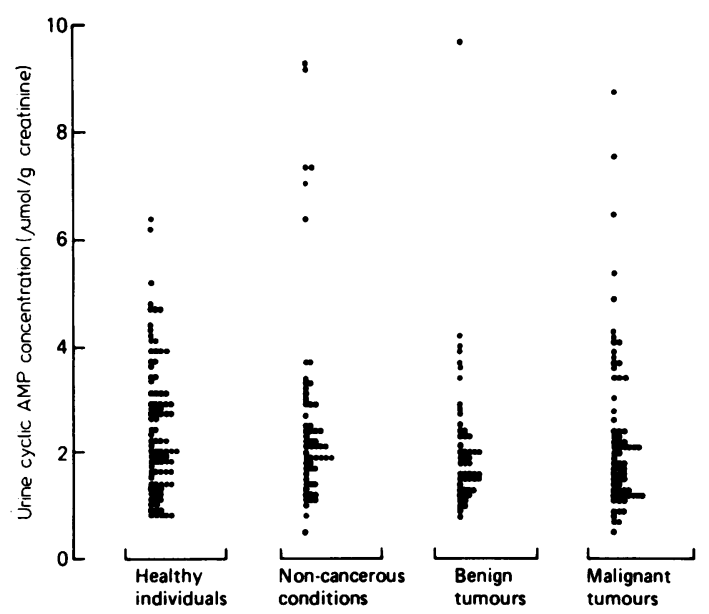

Fig. 2 Urine cyclic AMP concentrations in healthy individuals and in patients with non-cancerous conditions, benign tumours, or malignant tumours.

cyclic GMP-that is, the ratios for the malignant group are significantly lower $(p<0.001)$ than the ratios obtained for the other groups.

Table 1 presents a more detailed analysis of the urine cyclic GMP concentrations in the noncancerous group in terms of the particular type of disorder present. It was found that raised concentrations of urine cyclic GMP were more frequently associated with some disorders than with others. In severe upper respiratory tract infections, for example, the percentage of values which are higher than those found in the healthy group approaches that observed for the malignant group. For all the disor- 


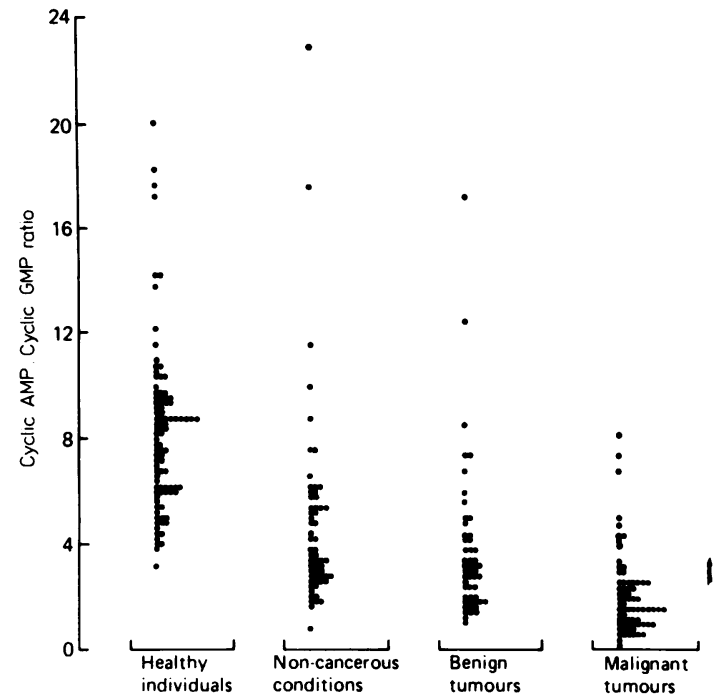

Fig. 3 Urine cyclic AMP:cyclic GMP ratios in healthy individuals and in patients with non-cancerous conditions, benign tumours, or malignant tumours.

ders listed, except psoriasis, the cyclic GMP concentrations are significantly higher than those found for the healthy group ( $<<0.001$ ).

Table 2 gives a more detailed analysis of the urine cyclic GMP concentrations for the patients with benign and malignant lesions of the breast. This was carried out by selecting from the benign group those patients in which the histology showed marked cellular hyperplasia, and by separating the malignant groups into those in which the lesion was limited to the breast and those in which there was metastatic spread. By applying such criteria, a very interesting picture emerged. In the benign group in which marked hyperplasia was noted, the urine cyclic GMP concentrations are significantly higher $(0.01>$ $p>0.001)$ than in the group in which this was not stated. Furthermore, in the marked hyperplasia group, $67 \%$ of the specimens have a urine cyclic GMP that is higher than the healthy reference range, whereas the figure for the rest of the benign group is only $20 \%$. Statistical comparison of the marked hyperplasia group with the limited malignant group indicated that their cyclic GMP concentrations are very similar $(p>0.05)$. With the development of the tumour and metastatic spread, however, the amount of cyclic GMP excreted is further significantly increased $(0.025>p>0.01)$.

Table 3 compares the mean urine cyclic GMP concentrations in cervical intraepithelial neoplasia with those in a group of patients with clinical cervical cancer. Concentrations in the latter group are significantly higher $(0 \cdot 01>p>0 \cdot 001)$ than those in the former, and also this increase is associated with an increased frequency of raised concentrations.

Table 4 shows the effect on cyclic GMP of removing all macroscopic signs of the tumour surgically. As a control, to show the effect of a surgical procedure on cyclic GMP concentrations, data are given

Table 2 Urine cyclic GMP concentrations in women with benign and malignant breast tumours

\begin{tabular}{|c|c|c|c|c|}
\hline \multirow[t]{2}{*}{ Group } & \multicolumn{2}{|c|}{$\begin{array}{l}\text { Urine cyclic GMP } \\
\text { ( } \mu \text { mol/g creatinine) }\end{array}$} & \multirow[t]{2}{*}{$p$ value } & \multirow{2}{*}{$\begin{array}{l}\text { Percentage increase } \\
\text { compared with healthy } \\
\text { group }^{*}\end{array}$} \\
\hline & Median & Range & & \\
\hline $\begin{array}{l}\text { Benign tumours (15) } \\
\text { Benign tumours- }\end{array}$ & 0.61 & $0.24-0.85$ & $>0.001$ & 20 \\
\hline marked hyperplasia (15) & $0 \cdot 80$ & $0.45-1.50$ & $<0.01$ & 67 \\
\hline $\begin{array}{l}\text { Malignant tumours- } \\
\text { limited to breast (10) }\end{array}$ & 0.73 & 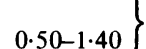 & $>0.05$ & 70 \\
\hline $\begin{array}{l}\text { Malignant tumours- } \\
\text { metastatic spread beyond } \\
\text { breast (11) }\end{array}$ & $1 \cdot 30$ & $0 \cdot 56-2 \cdot 00 \mathrm{~J}$ & $\begin{array}{l}>0.01 \\
<0.025\end{array}$ & 91 \\
\hline
\end{tabular}

*Range for healthy group given in Table 1.

Table 3 Urine cyclic GMP concentrations in women with cervical intraepithelial neoplasia and clinical cervical cancer

\begin{tabular}{|c|c|c|c|c|}
\hline \multirow[t]{2}{*}{ Group } & \multicolumn{2}{|c|}{$\begin{array}{l}\text { Urine cyclic GMP } \\
\text { (رmol/g creatinine) }\end{array}$} & \multirow[t]{2}{*}{$p$ value } & \multirow{2}{*}{$\begin{array}{l}\text { Percentage increase } \\
\text { compared with healthy } \\
\text { group* }\end{array}$} \\
\hline & Median & Range & & \\
\hline $\begin{array}{l}\text { Cervical intraepithelial } \\
\text { neoplasia (10) } \\
\text { Clinical cervical } \\
\text { cancer (15) }\end{array}$ & $\begin{array}{l}0.62 \\
0.93\end{array}$ & $\left.\begin{array}{l}0.25-1 \cdot 33 \\
0.51-4.77\end{array}\right\}$ & $\begin{array}{l}>0.001 \\
<0.01\end{array}$ & $\begin{array}{l}30 \\
93\end{array}$ \\
\hline
\end{tabular}

* Range for healthy group given in Table 1. 
Table 4 Effect of surgical treatment on urine cyclic GMP concentrations in prolapse and cancer patients

Urine cyclic GMP ( $\mu$ mol/g creatinine)

\begin{tabular}{|c|c|c|c|}
\hline \multicolumn{2}{|l|}{ Prolapse } & \multicolumn{2}{|l|}{ Cancer } \\
\hline Presurgery & Postsurgery & Presurgery & Postsurgery \\
\hline 0.43 & 0.44 & $1 \cdot 18$ & 0.92 \\
\hline 0.42 & 0.39 & 1.06 & 0.71 \\
\hline 0.71 & 0.60 & 4.70 & 0.77 \\
\hline 0.46 & 0.43 & 0.93 & 0.74 \\
\hline 0.47 & 0.46 & $1 \cdot 30$ & 0.42 \\
\hline 0.43 & 0.41 & 1.32 & $1 \cdot 14$ \\
\hline $0 \cdot 36$ & $0 \cdot 38$ & 0.77 & 0.52 \\
\hline 0.38 & 0.39 & 1.40 & 0.43 \\
\hline 0.47 & 0.41 & 1.84 & $0 \cdot 60$ \\
\hline 0.52 & 0.41 & 1.52 & 0.56 \\
\hline Median 0.45 & 0.41 & $1 \cdot 31$ & 0.72 \\
\hline
\end{tabular}

${ }^{*}$ Wilcoxon's paired analysis.

before and after a prolapse operation. As can be seen, the latter type of surgical procedure appeared to have no effect on cyclic GMP. In every cancer patient investigated in this way, the cyclic GMP concentration is less after removal of the tumour and this change is very significant $(p<0.01)$.

Urine cyclic GMP concentrations associated with the cytotoxic treatment of two different patient groups are illustrated in Table 5. Data from a precytotoxic group of patients are also presented for comparison. When treatment is associated with clinical remission, the cyclic GMP concentrations are significantly lower $(p<0.001)$ than those in the precytotoxic group. Concurrent with this change, the frequency of raised concentrations decreases from 100 to $15 \%$. Conversely, if patients do not exhibit remission, the urine cyclic GMP concentrations are not significantly lower $(p>0.05)$ than those in the precytotoxic group.

\section{Discussion}

While this work was in progress, a number of other preliminary studies reported that urine cyclic GMP concentrations can be raised in human cancer. ${ }^{7-11}$ The results from our study confirm and extend these previous findings. There is, however, considerable disagreement among all the studies as to the frequency of raised concentrations; some studies, like ours, have found increased concentrations in the majority of cancer patients investigated, ${ }^{711}$ whereas others have reported a frequency of raised urine cyclic GMP as low as $10-30 \% .{ }^{9}{ }^{10}$ Detailed examination of the latter studies, in the light of the results from the present investigation, suggests reasons for these lower frequencies.

In one study, ${ }^{9}$ in which a $10 \%$ frequency of raised urine cyclic GMP was reported, the control group was composed of healthy volunteers and women with benign tumours of the breast. As the present study has clearly shown that urine cyclic GMP concentrations may be raised in benign conditions, it might be anticipated that any comparison made using a control group containing such individuals would give a lower frequency of raised urine cyclic GMP in the cancer group. If our malignant group is compared with our benign group, only $28 \%$ of the values in the former group are raised. In another study, ${ }^{10}$ in which a 25 to $55 \%$ frequency of raised urine cyclic GMP was reported, $84 \%$ of the cancer patients were receiving chemotherapy; furthermore, this study gives no indication as to the effectiveness of the chemotherapy. Our study has shown that when chemotherapy is effective, urine cyclic GMP concentrations are substantially lower than when it is not. Successful chemotherapy in some patients, therefore, could account for this lower frequency of raised urine cyclic GMP previously observed. ${ }^{10}$

As yet, the reason for the increase in urine cyclic GMP is unknown. It could be speculated that this additional cyclic GMP arises directly from the cancer tissue through natural leakage into the extracellular fluid. Certainly, a number of studies on tumour biopsy specimens have reported raised tissue concentrations of cyclic GMP. ${ }^{1-4}$ Alternatively,

Table 5 Effect of cytotoxic treatment on urine cyclic GMP concentrations in ovarian cancer patients

\begin{tabular}{|c|c|c|c|c|}
\hline \multirow[t]{2}{*}{ Group } & \multirow[t]{2}{*}{$\begin{array}{l}\text { Tumour } \\
\text { detected }\end{array}$} & \multicolumn{2}{|c|}{$\begin{array}{l}\text { Urine cyclic GMP } \\
\text { ( } \mu \text { mollg creatinine) }\end{array}$} & \multirow{2}{*}{$\begin{array}{l}\text { Percentage increase } \\
\text { compared with healthy } \\
\text { group* }\end{array}$} \\
\hline & & Median & Range & \\
\hline \multirow{3}{*}{$\begin{array}{l}\text { I. Precytotoxic treatment (13) } \\
\text { II. Mid cytotoxics } \\
\text { No remission (11) } \\
\text { III. Mid cytotoxics } \\
\text { Complete remission (20) }\end{array}$} & + & $1 \cdot 33$ & $0.74-4.00$ & 100 \\
\hline & + & $1 \cdot 34$ & $0 \cdot 80-2 \cdot 33$ & 100 \\
\hline & - & 0.51 & $0 \cdot 15-0.81$ & 15 \\
\hline
\end{tabular}

Each group studied contains different patients.

Specimen of urine collected on day clinical observation made. 
the cyclic GMP may leak from the tumour tissue as a result of cell death. Tumour necrosis is a common finding in cancer.

The cellular concentration of cyclic GMP is controlled by the activity of two enzymes, guanylate cyclase and phosphodiesterase. The former controls its production and the latter its breakdown. Therefore, if the increased amounts of cyclic GMP originate in the tumour, then changes in either one or both of these enzymes could account for the increased production. Raised activity of guanylate cyclase ${ }^{2}$ and depressed activity of phosphodiesterase ${ }^{418}$ have been demonstrated in tumours. In view of the widespread distribution of these two enzymes throughout the body, however, it seems unlikely that the tumour is the only source of the cyclic GMP. Futhermore, the increase in the urine cyclic GMP did not appear to be strictly correlated with the total tumour burden. Even though concentrations were, on average, lower in localised tumours than in disseminated tumours, a patient with a large tumour burden did not necessarily have a higher cyclic GMP concentration than a patient with a smaller tumour burden.

It is very probable that the tumour produces substances which can also generally affect the level of cyclic GMP in the body, either by affecting its production in other tissues or by affecting its metabolism in the extracellular fluid. A previous study has shown that the activity of blood phosphodiesterase is considerably suppressed in cancer patients as compared to normal individuals. ${ }^{19}$ Since cyclic GMP excretion is reportedly not modified by the kidney, ${ }^{12}$ such a reduction in enzyme activity could lead to increased concentrations at excretion.

Urinary concentrations of cyclic AMP were unaffected by the presence of cancer and this finding is in agreement with the majority of previous reports. ${ }^{9-11}$ One previous study ${ }^{7}$ has reported a significant decrease in the excretion of cyclic AMP in malignancy, but the magnitude of this change is small, and one wonders at the relevance of such a change in view of the many factors which are known to affect cyclic AMP excretion.

Raised urine cyclic GMP concentrations were not just restricted to malignancy. Such changes were observed, but to a more limited extent, in the urine of some of the patients with benign growths and in the urine of some of the individuals with noncancerous conditions. This was especially noticeable in patients with severe disease of the respiratory tract, and in patients with benign lumps of the breast that histologically showed marked cellular hyperplasia. Other studies have also reported raised urine cyclic GMP in some patients with liver disease. ${ }^{911}$ Hence, the measurement of urine cyclic GMP has little value as a positive test for confirming the pres- ence of cancer in a previously undiagnosed patient.

Urine cyclic GMP measurements, however, do seem to have potential for monitoring the response of cancer patients to treatment, assuming the absence of certain other diseases. In patients given treatment resulting in the tumour burden being considerably reduced, urine cyclic GMP concentrations either fell (Table 4) or, if a pretreatment value was not available, were generally within the healthy reference range (Table 5). Conversely, if no clinical remission was detected, urine cyclic GMP concentrations remained raised. As we have also detected raised concentrations in patients with histologically confirmed cancer of the breast and cervix when total tumour burdens are apparently very low, this suggests that urine cyclic GMP may be very useful in the early detection of recurrences which would be more difficult to confirm by more conventional procedures. Studies are currently being carried out to evaluate the potential of urine cyclic GMP as a marker for monitoring tumour status in cancer patients receiving long-term chemotherapy. The interim results from these suggest that a recurrence can be detected prior to any clinical signs in the majority of patients. The details of this study are to be the subject of a future report.

The authors wish to thank the North of England Cancer Research Campaign for financial support for the project.

\section{References}

' De Rubertis FR, Chayoth R, Field JB. The content and metabolism of cyclic adenosine $3^{\prime}, 5^{\prime}$ monophosphate and cyclic guanosine $3^{\prime}, 5^{\prime}$ monophosphate in adenocarcinoma of the human colon. $J$ Clin Invest 1976;57:641-9.

${ }^{2}$ Shima S, Kawashima Y, Hirai M, Kouyama H. Studies on cyclic nucleotides in cancer. I. Adenylate, guanylate cyclase and protein kinases in prostatic sarcoma tissue. Biochim Biophys Acta 1976;444:571-8.

${ }^{3}$ Guerinot J, DeLarue C, Contesso G, Bohuon C. Adenosine 3',5' cyclic monophosphate and guanosine $3^{\prime}, 5^{\prime}$ cyclic monophosphate levels in human breast cancer tissue. Oncology 1977;34:261-3.

${ }^{4}$ Hickie RA, Thompson WJ, Strada SJ, Couture-Murillo B, Morris HP, Robinson GA. Comparison of cyclic adenosine $3^{\prime}, 5^{\prime}$ monophosphate and cyclic guanosine $3^{\prime}, 5^{\prime}$ monophosphate levels, cyclases and phosphodiesterases in Morris hepatoma and liver. Cancer Res 1977;37:3599-606.

${ }^{5}$ Criss WE, Murad F. Urinary excretion of cyclic guanosine 3',5' monophosphate and cyclic adenosine $3^{\prime}, 5^{\prime}$ monophosphate in rats bearing transplantable liver and kidney tumours. Cancer Res 1976;36:1714-6.

' Latner AL, Patterson SW, Turner GA. Adenosine 3',5' cyclic monophosphate and guanosine $3^{\prime}, 5^{\prime}$ cyclic monophosphate levels in tumour, plasma and urine during the growth of a fibrosarcoma in hamsters. Exp Cell Biol 1980;48:66-74.

${ }^{7}$ Gennari C, Francini G, Galli M, Lone F. Urinary excretion of cyclic adenosine $3^{\prime}, 5^{\prime}$ monophosphate and cyclic guanosine $3^{\prime}, 5^{\prime}$ monophosphate in malignancy. $J$ Clin Pathol 1978;31:735-41. 
${ }^{8}$ Guthrie D, Isah H, Latner AL, Turner GA. Urine cyclic GMP: a possible marker for cancer. IRCS Medical Science 1979;7:209.

' Wood PJ, Ross G, Smith CL. Plasma and urine cyclic nucleotide levels in malignant disease and cirrhosis of the liver. J Clin Pathol 1979;32:998-1002.

${ }^{10}$ Hunt NH, Smith B, Pembrey R. Cyclic nucleotide excretion in human malignancies. Clin Sci 1980;58:463-7.

" Dusheiko GM, Levin J, Kew MC. Cyclic nucleotides in biological fluids in hepatocellular carcinoma. Cancer 1981;47:113-8.

12 Broadus AE, Kaminsky NI, Hardman JG, Sutherland EW, Liddle GW. Kinetic parameters and renal clearances of plasma adenosine $3^{\prime}, 5^{\prime}$ monophosphate and guanosine $3^{\prime}, 5^{\prime}$ monophosphate in man. $J$ Clin Invest 1970;49:2222-36.

${ }^{13}$ Turner GA, Ellis RD, Guthrie D, Latner AL, Skillen AW, Ross WM. Studies of the levels of adenosine $3^{\prime}, 5^{\prime}$ cyclic monophosphate and guanosine $3^{\prime}, 5^{\prime}$ cyclic monophosphate in single urine specimens collected from a large population of healthy individuals. Ann Clin Biochem 1982;19:77-82.

${ }^{14}$ Goldberg ND, Haddox MK, Nicols SE, Glass DB, Sanford CH, Kuehl Jr FA, Estensen R. Biologic regulation through opposing influences of cyclic GMP and cyclic AMP. The Yin Yang hypothesis. Adv Cyclic Nucleotide Res 1975;5:307-38. is Sato T, Saito K, Takezowa J, et al. Urinary excretion of cyclic nucleotides and principal electrolytes in healthy humans of different ages. Clin Chim Acta 1981;110:215-25.

${ }^{16}$ Latner AL, Prudhoe K. A simplified competitive protein-binding assay for adenosine $3^{\prime}, 5^{\prime}$ monophosphate in plasma. Clin Chim Acta 1973;48:353-7.

${ }^{17}$ Popper H, Mander E, Mayer H. Zur Kreatininbestimmung im Blute. Biochemica Zeitschrift 1937;291:354-67.

${ }^{18}$ Curtis-Prior PB, Gibbons JRP, Yin-Ha Chan. Cyclic nucleotide phosphodiesterase activity of human normal and carcinomatous lung tissue. Lancet 1976;ii:1224-5.

${ }^{19}$ Ellis RD. Studies on the measurement of cyclic nucleotide phosphodiesterase in plasma and serum from normal individuals and cancer patients. MSc dissertation, University of Newcastle upon Tyne, 1978.

Requests for reprints to: Dr GA Turner, Cancer Research Unit, The Royal Victoria Infirmary, Newcastle upon Tyne NE1 4LP, England. 